\title{
Defining operative mortality: Impact on outcome reporting
}

\author{
Steven Maximus, MD, ${ }^{\mathrm{a}}$ Jeffrey C. Milliken, MD, ${ }^{\mathrm{a}}$ Beate Danielsen, PhD, ${ }^{\mathrm{b}}$ Junaid Khan, MD, \\ Richard Shemin, MD, ${ }^{d}$ and Joseph S. Carey, MD $^{\mathrm{a}}$
}

\section{ABSTRACT}

Objective: Death is an important outcome of procedural interventions. The death rate, or mortality rate, is subject to variability by definition. The Society of Thoracic Surgeons Adult Cardiac Surgery Database definition of "operative" mortality originally included all in-hospital deaths and deaths occurring within 30 days of the procedure. In recent versions of the Society of Thoracic Surgeons Adult Cardiac Surgery Database, "in-hospital" has been modified to include "patients transferred to other acute care facilities," and "deaths within 30 days unless clearly unrelated to the procedure" has been changed to "deaths within 30 days regardless of cause." This study addresses the impact of these redefinitions on outcome reporting.

Methods: The California Office of Statewide Health Planning and Development hospitalized patient discharge database was queried for the year 2009, the most recent year that data files could be linked to the vital statistics death files to include all-cause mortality. Isolated coronary artery bypass grafting, isolated valve, coronary artery bypass grafting valve, and percutaneous coronary intervention procedures were identified by International Classification of Diseases, Ninth Edition, Clinical Modification procedure codes. Percutaneous coronary intervention procedures were further divided into acute coronary syndrome (percutaneous coronary intervention acute coronary syndrome) and all other percutaneous coronary intervention (percutaneous coronary intervention no acute coronary syndrome). Deaths were counted by 5 methods depending on the time and place of occurrence: (1) in-hospital or during the index hospitalization; (2) inhospital + connected hospitalization, defined as a transfer to another acute care facility on the same day or within 24 hours of discharge; (3) inhospital +30 day, death during index hospitalization or within 30 days after the procedure; (4) in-hospital + connected +30 day readmission, death during index hospitalization, transfer to acute care facility, or deaths during readmission within 30 days; and (5) in-hospital + connected +30 day. To study the impact of these operative mortality definitions, we examined 5 different methods to track mortality and performed 2 separate analyses. The first analysis did not exclude any patients, and the second analysis excluded any patient who could not be accurately tracked after hospital discharge.

Results: In the first analysis with no patients excluded, a total of $17 \%(117 / 697)$ of surgical deaths and $31 \%$ (409/1324) of percutaneous coronary intervention deaths were counted after the original hospitalization. The highest percentage of posthospital deaths occurred after elective percutaneous coronary intervention: $45 \%$ (135/301). In surgical patients, the highest percentage of posthospital deaths occurred in coronary artery bypass grafting procedures: $20 \%(57 / 284)$. In the

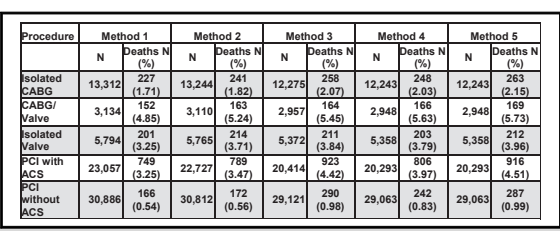

Operative mortality using 5 methods.

\section{Central Message}

Mortality rates for the same procedure can be variable and depend on the definition chosen.

\section{Perspective}

Depending on the definition of mortality used, the mortality rate for any procedure can vary, and these definitions and rankings may not be accurate.

See Editorial Commentary page 1110 .

\footnotetext{
From the ${ }^{\text {a Division }}$ of Cardiothoracic Surgery, Department of Surgery, University of California Irvine Medical Center, Orange, Calif; ${ }^{b}$ Health Information Solutions, Rocklin, Calif; ${ }^{\mathrm{c} D e p a r t m e n t}$ of Cardiothoracic Surgery, East Bay Cardiac Surgery Center, Oakland, Calif; and ${ }^{\mathrm{d}}$ University of California Los Angeles Ronald Reagan Medical Center, Los Angeles, Calif.

Read at the 41st Annual Meeting of The Western Thoracic Surgical Association, Whistler, British Columbia, Canada, June 24-27, 2015.
}

Received for publication June 27, 2015; revisions received Sept 15, 2015; accepted for publication Oct 1, 2015; available ahead of print Feb 11, 2016.

Address for reprints: Steven Maximus, MD, 333 The City Drive, Suite 1600, Orange, CA 92868 (E-mail: smaximus@uci.edu). $0022-5223 / \$ 36.00$

Copyright (c) 2016 by The American Association for Thoracic Surgery http://dx.doi.org/10.1016/j.jtcvs.2015.10.062 


\section{Abbreviations and Acronyms \\ ACC-NCDR $=$ American College of Cardiology \\ National Cardiovascular Data \\ Registry \\ ACS = acute coronary syndrome \\ CABG = coronary artery bypass grafting \\ OSHPD $=$ Office of Statewide Health Planning and Development \\ PCI = percutaneous coronary intervention \\ STS-NDB $=$ Society of Thoracic Surgeons \\ National Database}

second analysis, with untrackable patients excluded, hospital deaths included $12 \%(161 / 1324)$ for percutaneous coronary intervention compared with $4 \%$ (30/697) for surgical procedures.

Conclusions: A significant percentage of procedural deaths occur after transfer or discharge from the index hospital. This is especially evident in the percutaneous coronary intervention group. These findings illustrate the importance of the definition of "operative" mortality and the need to ensure accuracy in the reporting of data to voluntary clinical registries, such as the Society of Thoracic Surgeons Adult Cardiac Surgery Database and National Cardiovascular Data Registry. (J Thorac Cardiovasc Surg 2016;151:1101-10)

Evaluating the care delivered by hospitals has been the goal of quality reporting programs, with accurate reporting being imperative for analysis and comparisons of outcomes. This is particularly emphasized when outcomes for procedural interventions are analyzed and compared. Although postoperative death is an important measurable outcome, operative morality does not have a universal definition. ${ }^{1,2}$ Several definitions of operative morality have been used in various quality programs, with some defining postoperative mortality as a death that occurs during the same admission, and others defining postoperative death within a standardized time interval after surgery, ${ }^{2}$ with 30-day follow-up most common. However, it is difficult for some hospitals to track 30-day mortality, because patients may be referred from remote locations and some centers may not have the resources to track all mortality after discharge. ${ }^{1}$

The Society of Thoracic Surgeons National Database (STS-NDB) separately collects both in-hospital and 30-day mortality status, and has revised its definition of operative mortality to ensure more accurate and consistent measurement of outcomes. The original definition of operative mortality included (1) all deaths occurring during the hospitalization in which the operation was performed, even if after 30 days; and (2) those deaths occurring after discharge from the hospital but within 30 days of the procedure unless the cause of death is clearly unrelated to the operation. This definition was further updated in 2011 to address the issue of patients transferred to other acute care facilities. The most recent iteration of operative mortality appeared in 2014, which defined operative mortality as (1) all deaths, regardless of cause, occurring during the hospitalization in which the operation was performed, even if after 30 days (including patients transferred to other acute care facilities); and (2) all deaths, regardless of cause, occurring after discharge from the hospital but before the end of the 30th postoperative day. ${ }^{3}$ To study the impact of these changes to the STS-NDB operative mortality definitions, we examined 5 different methods to track mortality and performed 2 separate analyses. The first analysis did not exclude any patients, and the second analysis excluded any patient who could not be accurately tracked after hospital discharge. The aim of this study was to demonstrate the effect of differences in mortality definition methodology and the impact of the definition on morality rates.

\section{MATERIALS AND METHODS}

The California Office of Statewide Health Planning and Development (OSHPD) hospitalized Patient Discharge Database was queried for the year 2009, the most recent year that data files could be linked to the vital statistics death files to include all-cause mortality. The OSHPD collects inpatient discharge data from all licensed inpatient hospitals in California. Each record in the dataset corresponds to an individual inpatient hospital discharge.

The California Cardiac Surgery and Intervention Project, a project of the California Society of Thoracic Surgeons, collects data from the OSHPD Patient Discharge Database on all cardiac surgery and percutaneous coronary intervention $(\mathrm{PCI})$ procedures performed in the state. The data files have patient-level data and include information on patient demographics, diagnosis and procedure codes, payment source, admission source, and all-cause mortality. Because California requires licensed hospitals to submit data on all discharged patients biannually, a $100 \%$ collection rate is ensured for patients undergoing cardiac surgery or PCI. The OSHPD includes confidential information about health care outcomes to qualified California Society of Thoracic Surgeons investigators who are faculty members of the University of California. The California Cardiac Surgery and Intervention Project reports volume and outcomes on all cardiac surgery and interventions on its Web site to provide quality improvement data for health care givers and other stakeholders.

We queried the database from January 1, 2009, to December 31, 2009, for all patients undergoing a primary procedure of isolated coronary artery bypass grafting $(\mathrm{CABG})$, isolated valve, $\mathrm{CABG}$ valve, and $\mathrm{PCI}$ procedures. These patients were identified by International Classification of Diseases, 9th Revision, Clinical Modification procedure codes. PCI procedures were further divided into acute coronary syndrome (ACS) (PCI with ACS) and all other PCI (PCI without ACS) on the basis of the presence of an admission diagnosis code for acute myocardial infarction code (410.xx).

The OSHPD inpatient discharge record also includes patient disposition. Patients transferred to another facility can be tracked through connected hospitalizations on the basis of a record linkage number that uniquely identifies the patient. We included in our mortality outcome 


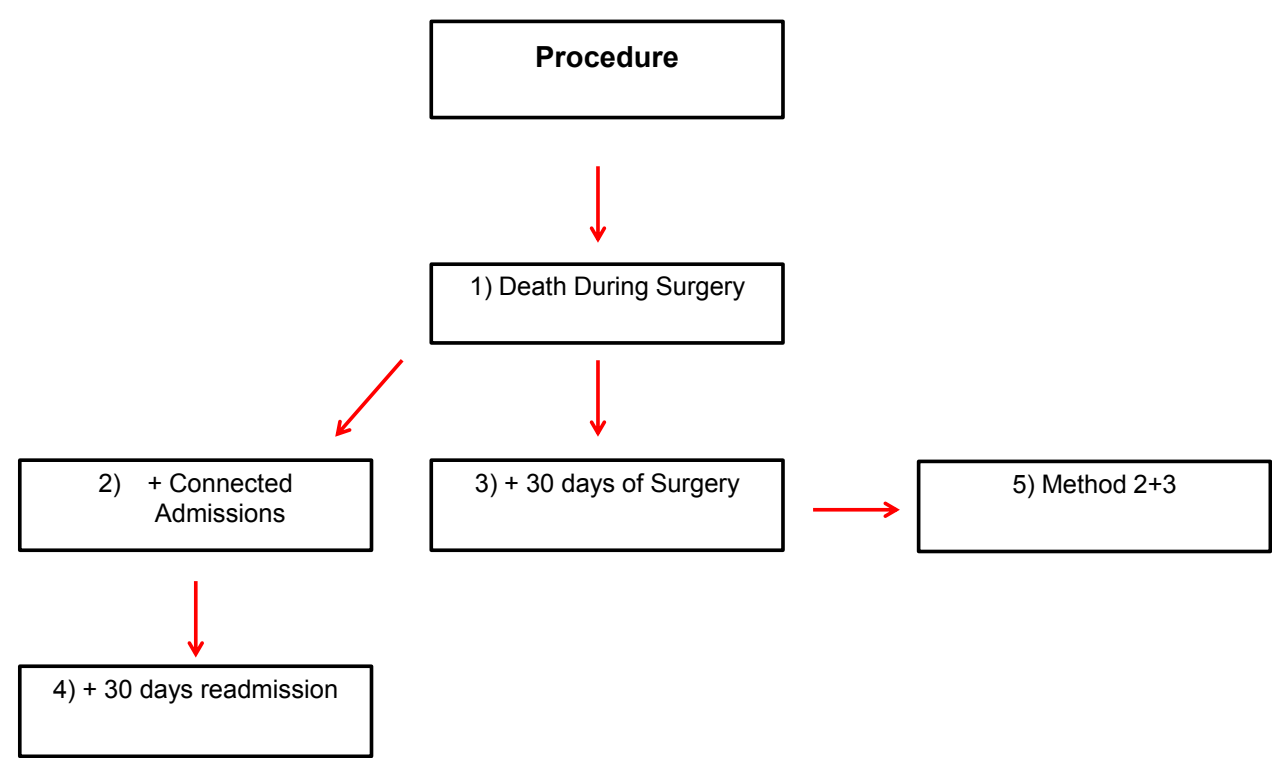

FIGURE 1. Method of calculating mortality.

deaths that occurred after the index admission or a death that occurred after a subsequent connected acute care admission. Patients who were discharged to home, a skilled nursing facility, long-term care, home health service, or nursing home were considered survivors. Two admissions were considered connected if the disposition at the transferring facility was acute care or the admission source at the facility the patient was transferred to was acute care and the type of care provided was acute inpatient care. In addition, the discharge date at the transferring facility had to be within 1 day of the admission date at the facility a patient was transferred to.

Deaths were counted by 5 methods depending on the time and place of occurrence (Figure 1):

1. Death during surgery admission: This definition includes any death that occurs during the hospital stay where the procedure was performed, regardless of time.

2. Death during surgery admission and connected admission: This includes the previous definition and any deaths occurring after connected transfer to another acute care facility, regardless of time elapsed after the procedure.

3. Death during surgery admission and within 30 days of surgery: death during the surgery admission or within 30 days after the procedure regardless of location. This definition is equivalent to older STS-NDB definitions of operative mortality.

4. Death during surgery admission and connected admission and at readmission within 30 days of surgery: death during the procedure admission, during connected hospitalization, plus any deaths occurring within 30 days during readmission to another acute care facility.
5. Death during surgery admission and connected admission and within 30 days of surgery: death during procedure admission or connected hospitalization, or within 30 days of procedure from any cause or at any location. This definition is equivalent to the current STS-NDB definition of operative mortality.

\section{RESULTS}

Approximately $8 \%$ of patients did not have unique identifiers and could not be followed through connected hospitalizations. For this reason, 2 analyses were performed. The first included all patients without exclusion. The second analysis excluded any patient who could not be followed longitudinally after an in-hospital procedure, regardless of the reason. Table 1 shows the results with all patients included regardless of the ability to determine transfer status and Figure 2 illustrates these results further in chart format.

In the second analysis (Table 2), patients who could not be tracked were excluded. For method 1, the definition includes only deaths that occurred in the hospital where the procedure occurred, so all procedures and outcomes were included. In method 2, patients who were missing

TABLE 1. Number of patients excluded

\begin{tabular}{|c|c|c|c|c|c|c|}
\hline & 2009 & Method 1 & Method 2 & Method 3 & Method 4 & Method 5 \\
\hline Procedure & Patients N & Deaths N $(\%)$ & Deaths N $(\%)$ & Deaths N $(\%)$ & Deaths N (\%) & Deaths $\mathbf{N}(\%)$ \\
\hline Isolated CABG & 13,312 & $227(1.71)$ & $241(1.81)$ & $273(2.05)$ & $267(2.01)$ & $284(2.13)$ \\
\hline CABG/valve & 3134 & $152(4.85)$ & $163(5.20)$ & $172(5.49)$ & $177(5.65)$ & $181(5.78)$ \\
\hline Isolated valve & 5794 & $201(3.25)$ & $214(3.69)$ & $223(3.85)$ & $223(3.85)$ & $232(4.00)$ \\
\hline PCI with ACS & 23,057 & $749(3.25)$ & $789(3.42)$ & 1013 (4.39) & $908(3.94)$ & $1023(4.44)$ \\
\hline PCI without ACS & 30,886 & $166(0.54)$ & $172(0.56)$ & $300(0.97)$ & $255(0.83)$ & $301(0.97)$ \\
\hline
\end{tabular}

A total of $17 \%$ (117/697) of surgical deaths and 31\% (409/1324) of PCI deaths were counted after the original hospitalization. The highest percentage of post-hospital deaths occurred after elective PCI: $45 \%$ (135/301). In surgical patients, the highest percentage of post-hospital deaths occurred in CABG procedures: 20\% (57/284). CABG, Coronary artery bypass grafting; $P C I$, percutaneous coronary intervention; $A C S$, acute coronary syndrome. 


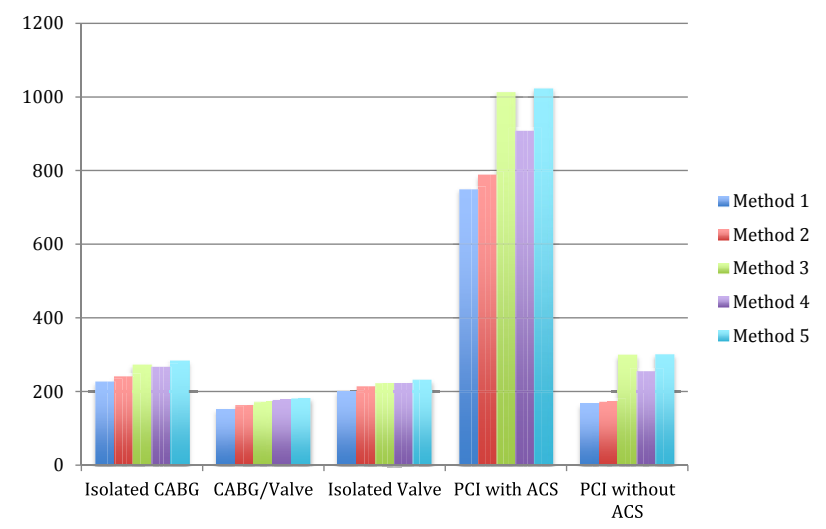

FIGURE 2. No patients excluded (values based on Table 1). $C A B G$, Coronary artery bypass grafting; $P C I$, percutaneous coronary intervention; $A C S$, acute coronary syndrome.

across admissions patient identifiers (usually an encrypted Social Security number) were excluded, which resulted in a reduction in the total number of patients (denominator). To retain an accurate percentage of operative mortality, deaths (numerator) that occurred in "untrackable" patients were also excluded. In methods 3,4 , and 5, out-of-state patients, patients who left against medical advice, and patients with missing across admissions patient identifiers were excluded. This also caused a reduction in both the denominator and the numerator in these groups. Figure 3 further illustrates these findings.

Despite the reduction in patient numbers, the mortality percentages were essentially the same. Table 2 could be considered statistically correct because the denominator includes the population at risk for the event being "counted" in the numerator (in this case the population at risk is the number of procedure patients, and the numerator is the event, which is death). Exclusions resulted in a variable number of procedures, depending on the definition. Not only is mortality (numerator) affected depending on the definition used, but also the denominator is dependent on the definition and method used. Despite these effects, mortality percentages were basically unchanged.

In both tables, method 1 (death during surgery admission) resulted in the lowest mortality number for all procedures, and method 5 (death during surgery admission or connected admission or within 30 days of surgery) gave the highest mortality percentage for all procedures. The PCI groups were found to have a larger percentage of deaths occurring after hospital discharge and within 30 days of the procedure compared with surgical groups. Out of hospital deaths are captured by methods 3 and 5 , and the difference between method 4 , which captures all in hospital deaths, and method 5 is an estimate of out of hospital mortality. Out of hospital deaths were $12 \%$ (161/1324) for PCI and 4\% (30/697) for surgical procedures. Method 4 also captures the largest percentage of "operative" deaths for surgical patients compared with method 5, which is the current STS-NDB definition: $96 \%(667 / 697)$.

\section{DISCUSSION}

We evaluated the impact of redefinition of operative mortality by counting deaths by 5 methods, each of which was dependent on the time and place of occurrence. The data collected show that a large percentage of procedural deaths occur after transfer or discharge from the index hospital, particularly in the PCI groups. We found that a larger percentage of deaths occurred after transfer or discharge from the index hospital in the PCI groups, which was in contrast to the mortality counts in the surgical groups. PCI mortality was more dependent on the method used to define mortality compared with surgical patients, with a larger percentage of deaths occurring after hospital discharge and within 30 days of the procedure. This finding has implications in terms of how procedural quality assessment should be defined.

Method 5 includes mortality after the index admission, mortality after connected acute care admissions, and deaths that occurred within 30 days of the procedure regardless of location. This definition results in a higher mortality level compared with definition 1 in patients undergoing PCI. Approximately half the mortality after PCI without ACS occurred after hospital discharge and within 30 days of the procedure. On the basis of the data in this study, definition 5 is the most encompassing and is the current definition used by the STS and should be applied to other clinical registries, such as the American College of Cardiology

TABLE 2. Untrackable patients excluded

\begin{tabular}{|c|c|c|c|c|c|c|c|c|c|c|}
\hline \multirow[b]{2}{*}{ Procedure } & \multicolumn{2}{|c|}{ Method 1} & \multicolumn{2}{|c|}{ Method 2} & \multicolumn{2}{|c|}{ Method 3} & \multicolumn{2}{|c|}{ Method 4} & \multicolumn{2}{|c|}{ Method 5} \\
\hline & $\begin{array}{c}\text { Patients } \\
\text { N }\end{array}$ & $\begin{array}{l}\text { Deaths } \\
\text { N }(\%)\end{array}$ & $\begin{array}{c}\text { Patients } \\
\text { N }\end{array}$ & $\begin{array}{l}\text { Deaths } \\
\text { N }(\%)\end{array}$ & $\begin{array}{c}\text { Patients } \\
\text { N }\end{array}$ & $\begin{array}{l}\text { Deaths } \\
\text { N }(\%)\end{array}$ & $\begin{array}{c}\text { Patients } \\
\text { N }\end{array}$ & $\begin{array}{l}\text { Deaths } \\
\text { N }(\%)\end{array}$ & $\begin{array}{c}\text { Patients } \\
\text { N }\end{array}$ & $\begin{array}{l}\text { Deaths } \\
\text { N }(\%)\end{array}$ \\
\hline Isolated CABG & 13,312 & $227(1.71)$ & 12,445 & $226(1.82)$ & 12,275 & 254 (2.07) & 12,243 & $248(2.03)$ & 12,243 & $263(2.15)$ \\
\hline CABG/valve & 3134 & $152(4.85)$ & 2998 & $155(5.17)$ & 2957 & $161(5.44)$ & 2948 & $166(5.63)$ & 2948 & $169(5.73)$ \\
\hline Isolated valve & 5794 & $201(3.25)$ & 5487 & $202(3.68)$ & 5372 & $203(3.78)$ & 5358 & 203 (3.79) & 5358 & $212(3.96)$ \\
\hline PCI with ACS & 23,057 & $749(3.25)$ & 20,776 & $699(3.36)$ & 20,414 & 913 (4.47) & 20,293 & 806 (3.97) & 20,293 & $916(4.51)$ \\
\hline PCI without ACS & 30,886 & $166(0.54)$ & 29,516 & $162(0.55)$ & 29,121 & $287(0.99)$ & 29,063 & $242(0.83)$ & 29,063 & $287(0.99)$ \\
\hline
\end{tabular}

$C A B G$, Coronary artery bypass grafting; $P C I$, percutaneous coronary intervention; $A C S$, acute coronary syndrome. 


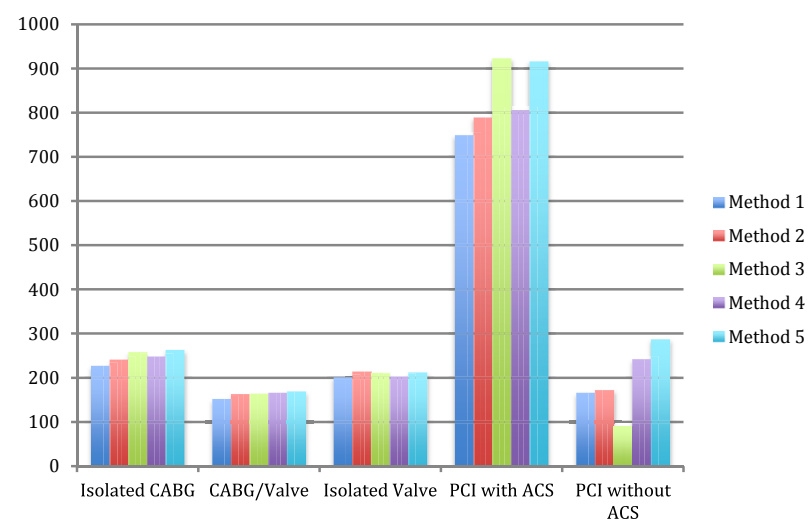

FIGURE 3. Untrackable patients excluded (values based on Table 2). $C A B G$, Coronary artery bypass grafting; $P C I$, percutaneous coronary intervention; $A C S$, acute coronary syndrome.

National Cardiovascular Data Registry (ACC-NCDR). According to the NCDR Web site, outcome measures include PCI in-hospital mortality and 30-day readmission; however, overall 30-day mortality is not included. ${ }^{4}$ In comparing the PCI groups and the surgery groups, a patient death is more likely to be picked up through an inpatient readmission within 30 days for the surgical group, whereas information after home discharge is important for a complete picture of mortality after PCI. Of note, patients discharged to skilled nursing facilities did not count as a connected admission, because skilled nursing facilities are not required to report these data. The issue of whether death in a skilled nursing facility should be counted is a subject of some debate. By using definitions 3, 4, and 5, patients who die within 30 days of a procedure would be counted as an operative death, but those patients who die after 30 days at a skilled nursing facility would not be counted. This is a potential source of "gaming" the operative mortality measure. Furthermore, because of issues with subject hospitals tracking readmission to other facilities, and the occurrence of out of hospital death, substantially more diligence and resources are needed to ensure accurate follow-up on the part of reporting hospitals. It is likely that this is a variable that affects accuracy in self-reporting databases.

Our data show that death should have a clear definition in any registry database, because the performance can significantly vary depending on the definition of death used. Previous studies have shown that altering the parameters of the definition of mortality results in a redistribution of outcomes. In a study by Johnson and colleagues, ${ }^{5}$ outcomes at 43 Veterans Affairs hospitals were measured by redefining operative mortality in patients who underwent $\mathrm{CABG}$ surgery. The definition of operative death was changed from the traditional 30-day mortality definition (any death occurring within 30 days after surgery, regardless of cause, in or out of the hospital) to 30-day mortality plus all procedure-related mortality (any death that occurred 30 days to 6 months after surgery that was deemed to be a direct result of a complication of the surgery). With this change in definition, the ranking of $86 \%$ of the hospitals in the study changed, with $21 \%$ changing their quartile rank and $11 \%$ changing outlier status. Their study was able to show that by altering the definition of mortality, the hospital profiles of postoperative mortality from CABG surgery were affected. Likewise, by readjusting the definition of mortality by using different parameters for time and place of occurrence, we were able to show deaths that may have not been captured under previous definitions of mortality.

Monitoring surgical outcomes is necessary to promote quality improvement. ${ }^{6}$ It is vital that definitions be standardized to provide achievable benchmarks and identify hospitals with potential quality problems. It is equally important that data be accurate and have standardization of definitions, because data collection and public reporting without clear parameters can have important implications on comparative health care outcomes. Furthermore, it is imperative that data are accurate and be collected and reported by sources that are verified and audited. There has been a push for more outcome data to be made publically available, but this should be done with caution. Reporting from public consumer groups should be approached conservatively, because data reported from these sources can vary depending on the definition, as shown by our data. This has been shown in previous studies, with Joynt and colleagues ${ }^{7}$ showing that states with mandatory public reporting for PCI outcomes have been found to have substantially lower rates of PCI among patients with acute myocardial infarction compared with states without public reporting. This finding was also demonstrated in a study by Aggarwal and colleagues, ${ }^{8}$ who recommended the inclusion of 30-day mortality in the definition, because approximately half of the PCI-related deaths occurred within 30 days postdischarge. Several studies have shown that public release of outcome data does not change the behavior of consumers, ${ }^{9,10}$ with few patients using these data to select a doctor or hospital. ${ }^{11}$ Previous studies have shown that public reporting can influence clinical decision making, with procedure rates declining in high-risk patients after the implementation of public reporting. ${ }^{7,12}$ Health care providers and clinical institutions should be the main audience of these data, because results from outcomes can be used for targeting areas of improvement for both individuals and institutions. This approach has been shown to lead to improvement in outcomes without public release of data. ${ }^{13,14}$

\section{Study Limitations}

A potential limitation of this study is that the data from this project come from an administrative dataset that is 
dependent on administrative and billing coding. Administrative databases are designed for their own individual purposes (ie, administrative claims) and not for clinician inference. ${ }^{15}$ Although not designed for clinical inference, several studies have validated the use of administrative data in predicting potential quality problems. ${ }^{16}$ Furthermore, models using administrative data to predict postoperative mortality have been shown to be improved with the addition of a small number of clinical variables, making them useful when used for quality improvement efforts. ${ }^{17}$ The administrative data are limited by the need to use International Classification of Diseases, 9th Revision, Clinical Modification codes for diagnoses and procedures, and do not support clinical risk stratification. The data also are dependent on the California Vital Statistics death file, and the currently available death file only allows us to complete assessment of death status within 30 days of surgery for 2009 and earlier years, which leads to a gap of 5 years when used as a source of outcome information after cardiac procedures. The death files are only made available after a period of 5 years, so 2009 is the most recent data that are accessible. Furthermore, the inability to follow patients who did not have patient identifiers leads to changes in both the numerator and the denominator of our mortality calculation depending on the definition. Patients who were transferred to skilled nursing facilities were also not counted in mortality calculations unless they died within 30 days of the procedure, as previously discussed. Any patient who died in a skilled nursing facility beyond 30 days was not included in the numerator or denominator in this report because they were considered to be discharged. However, it is important and unique to be able to collect accurate data on all revascularization procedures in the state of California, including both CABG and PCI, because reporting is mandatory. Outcome information is secure in that data points are actual hospital admissions or validated deaths. These results may not be applicable across the United States, because currently only New York, New Jersey, Pennsylvania, Massachusetts, and California require outcome reporting after cardiac intervention. ${ }^{4}$

\section{CONCLUSIONS}

Outcome reporting has had a significant impact on shaping clinical practices, with feedback being used to improve surgical outcomes over the past decade. ${ }^{18,19}$ This report is the first to recognize the substantial and potentially unreported mortality after hospital discharge in California patients who have undergone PCI. It is evident that mortality rates for the same procedure can be variable and depend on the definition chosen. The findings of this study illustrate the importance of the definition of operative mortality and the need to ensure accuracy in the reporting of data to voluntary clinical registries such as the STS-NDB and ACC-NCDR.

\section{Conflict of Interest Statement}

J.K. reports consulting fees for Edwards Lifesciences. All other authors have nothing to disclose with regard to commercial support.

\section{References}

1. Jacobs JP, Mavroudis C, Jacobs ML, Maruszewski B, Tchervenkov CI, LacourGayet FG, et al. What is operative mortality? Defining death in a surgical registry database: a report from the STS Congenital Database Task Force and the Joint EACTS-STS Congenital Database Committee. Ann Thorac Surg. 2006;81: 1937-41.

2. Overman DM, Jacobs JP, Prager RL, Wright CD, Clarke DR, Pasquali SK, et al. Report from the Society of Thoracic Surgeons National Database Workforce: clarifying the definition of operative mortality. World J Pediatr Congenit Heart Surg. 2013;4:10-2.

3. Society of Thoracic Surgeons. STS adult cardiac surgery database specifications. Available at: http://www.sts.org/sites/default/files/documents/STSAdultCVData SpecificationsV2_81.pdf. Accessed May 15, 2015.

4. Shahian DM, Edwards FH, Jacobs JP, Prager RL, Normand SL, Shewan CM, et al. Public reporting of cardiac surgery performance: Part 1-history, rationale, and consequences. Ann Thorac Surg. 2011;92:S2-11.

5. Johnson ML, Gordon HS, Petersen NJ, Wray NP, Shroyer AL, Grover FL, et al. Effect of definition of mortality on hospital profiles. Med Care. 2002;40:7-16.

6. Davenport DL, Hyderson WG, Khuri SF, Mentzer RM Jr. Preoperative risk factors and surgical complexity are more predictive of costs than postoperative complications: a case study using the National Surgical Quality Improvement Program (NSQIP) database. Ann Surg. 2005;242:464-8.

7. Joynt KE, Blumenthal DM, Orav EJ, Resnic FS, Jha AK. Association of public reporting for percutaneous coronary intervention with utilization and outcomes among Medicare beneficiaries with acute myocardial infarction. JAMA. 2012; 308:1460-8.

8. Aggarwal B, Ellis SG, Lincoff A, Kapadia SR, Cacchione J, Raymond R, et al. Cause of death within 30 days of percutaneous coronary intervention in an era of mandatory outcome reporting. J Am Coll Cardiol. 2013;62:409-15.

9. Marshall MN, Shekelle PG, Leatherman S, Brook RH. The public release of performance data: what do we expect to gain? A review of the evidence. JAMA. 2000;283:1866-74.

10. Ketelaar NA, Faber MJ, Flottorp S, Rygh LH, Deane KH, Eccles MP. Public release of performance data in changing the behaviour of healthcare consumers, professionals or organisations. Cochrane Database Syst Rev. 2011 Nov 9;CD004538.

11. Schneider E, Lieberman T. Publicly disclosed information about the quality of health care: response of the US public. Qual Health Care. 2001;10:96-103.

12. Peberdy M, Donnino MW, Callaway CW, Dimaio JM, Geocadin RG, Ghaemmaghami CA, et al. Impact of percutaneous coronary intervention performance reporting on cardiac resuscitation centers: a scientific statement from the American Heart Association. Circulation. 2013;128:762-73.

13. Schneider E. Measuring mortality outcomes to improve health care: rational use of ratings and rankings. Med Care. 2002;40:1-3.

14. O'Connor GT, Plume SK, Olmstead EM, Morton JR, Maloney CT, Nugent WC, et al. A regional intervention to improve the hospital mortality associated with coronary artery bypass graft surgery. JAMA. 1996;275:841-6.

15. Geraci JM, Johnson ML, Gordon HS, Petersen NJ, Shroyer AL, Grover FL, et al. Mortality after cardiac bypass surgery: prediction from administrative versus clinical data. Med Care. 2005;43:149-58.

16. Gordon HS, Johnson ML, Wray NP, Petersen NJ, Henderson WG, Khuri SF, et al. Mortality after noncardiac surgery: prediction from administrative versus clinical data. Med Care. 2005;43:159-67.

17. Ivanovic J, Seely AJ, Anstee C, Villeneuve PJ, Gilbert S, Maziak DE, et al. Measuring surgical quality: comparison of postoperative adverse events with the American college of surgeons NSQIP and the Thoracic Morbidity and Mortality classification system. J Am Coll Surg. 2014;218:1024-31.

18. Birkmeyer JD. Progress and challenges in improving surgical outcomes. $\mathrm{Br} \mathrm{J}$ Surg. 2012;99:1467-9.

19. Reames BN, Ghaferi AA, Birkmeyer JD, Dimick JB. Hospital volume and operative mortality in the modern era. Ann Surg. 2014;260:244-51. 
Key Words: cardiac surgery, operative mortality, outcome reporting, CABG, PCI

\section{Discussion}

Dr Maximus. Evaluating the care delivered by hospitals is the goal of quality reporting programs, with accurate reporting imperative for analysis and comparison of outcomes. This is particularly important when outcomes for procedural interventions are analyzed and compared. Death, or operative mortality, is the most important outcome for procedural interventions. Although postoperative death is an important measurable outcome, operative mortality does not have a universal definition. There are several definitions of mortality that are used in various quality reporting programs. Some define an operative mortality as one that occurs during the same admission, death before discharge, and others define it as a certain time interval after surgery, most commonly 30 days. Why is this important? Ratings on mortality are reported by groups such as Consumer Reports, which are based on information from the STS. These reports are marketed to the general public as having accurate information and rate hospitals on the basis of mortality rates. Our hypothesis was that depending on the definition of mortality used, the mortality rate for any procedure can vary and that these definitions and rankings may not be accurate. As I mentioned before, there are multiple definitions of mortality. The American Heart Association, for example, uses mortality within 30 days, whereas the American College of Cardiology, American National Cardiovascular Data Registry, American College of Cardiology, and Cardiovascular Data Registry only track mortality that occurs in the hospital. The STS has revised its definition of operative mortality throughout the years. This is a 2011 definition that includes all deaths occurring during the acute episode of care in which the operation was performed; this also includes patient transfer to other acute care facilities even after 30 days. The second part of this definition is deaths occurring after discharge from the hospital, but within 30 days of the procedure, unless the cause of death is clearly unrelated to the operation. Now this is the 2014 definition, which is the most recent, and this includes all deaths regardless of cause occurring during the hospitalization in which the operation was performed, even if after 30 days. This includes patients transferred to other acute care facilities, and the second part is all deaths regardless of cause, occurring after discharge from the hospital but before the end of the 30th postoperative day. We used the California OSHPD Hospitalized Patient Discharge Data Base to use 5 different methods to count postoperative mortality; 2009 was the most recent year data files could be linked to vital statistic death files, which is the year we looked at, and we created the database from January 1,
2009, to December 31, 2009, using patients undergoing CABG, isolated valve, CABG and valve, and PCI procedures. These were all looked at using International Classification of Diseases, 9th Revision codes. PCI procedures were further divided into patients with ACS, which is PCI with ACS, and all other PCI, which basically is elective PCI. This was based on the presence of admission diagnosis codes for acute myocardial infarction. For the definitions we used, the first was death during surgery admission; this is basically the classic definition: any patient who dies while in the hospital where they had the procedure done, regardless of time. The second one is death during surgery admission or connected admission. This is the same as the previous definition but also includes patients who are transferred to another acute care facility, again regardless of time lapse after the procedure. The third definition is death during surgery admission, within 30 days of surgery. This is one of the older STS definitions of operative mortality. The fourth definition we used was death during surgery admission or connected admission or readmission within 30 days of surgery; this includes death during the procedure admission, any transfer, basically, or any patient who is readmitted to another acute care facility within 30 days and dies. This does not include out of hospital deaths. The final definition is probably the most encompassing definition and is closest to the one the STS uses currently. This is death during a surgery admission or a transfer basically, or connected admission, or within 30 days of surgery. One caveat is that skilled nursing facility transfers or skilled nursing facilities may or may not be counted as an acute care facility, because not all skilled nursing facilities report their outcomes or data.

So these are our results. We actually did 2 separate analyses, so I'll be showing 2 different tablets because approximately $8 \%$ of patients did not have a unique identifier such as a Social Security number of record linkage number, so they could not be followed through connected hospitalizations or transfers. This first analysis is the one I show here. This has no inclusions due to lack of follow-up. This tablet shows the results of all patients regardless of the ability to follow up. As you can see, for example, isolated CABG, operative mortality ranged from $1.71 \%$ to $2.13 \%$. Method 5 obviously was the most inclusive. If you look at PCI without ACS, the range was $0.54 \%$ and then doubled using method 5 , and it was $0.97 \%$. As I mentioned, method 5 was the most inclusive. This gave 697 surgical deaths, and $17 \%$ of these deaths occurred after the hospitalization. A total of 409 PCI deaths occurred after the indexed hospitalization, which was approximately $31 \%$. The highest percentage of post-hospital deaths occurred after elective PCI, which was $45 \%$. As you can see, if you use the ACC-NCDR definition of mortality, PCI with ACS is $3.25 \%, 0.54 \%$, that's death during surgery admission. However, if you use the STS definition of mortality, it 
goes up to $4.44 \%$ for PCI with ACS and then 0.97 for PCI with ACS. These mortality rates and results can be considered underreported because the denominator is not adjusted; it includes patients who cannot be tracked. This was our second analysis in which untrackable patients were excluded. Patients who did not have any unique identifiers were excluded and gave a variable number of procedures depending on the definition used. This is due to exclusion criteria. We excluded out-of-state patients, patients who left against medical advice, and any patient without a unique identifier. This caused a reduction in the denominator and the numerator in this group. However, this did not result in significant change in the overall mortality rates. This table can be considered more statistically accurate, because the denominator includes the population at risk for the event being counted in the numerator.

In summary, a significant number of cardiac procedural deaths occurred after transfer at discharge from the index hospitalization, $17 \%$ in the surgical group compared with $31 \%$ in the PCI group. PCI mortality was more dependent on the method used to define mortality compared with the surgical patients, and a larger percentage of deaths occurred after hospital discharge and within 30 days of the procedure. You can see that this was almost doubled in the PCI group, and we think that has significant implications on outcome reporting. By comparing the PCI group with the surgery groups, you can see that after home discharge it is important for a complete picture of mortality after PCI. The issue of whether or not death during skilled nursing facility admission should be counted as an operative mortality is a subject of debate. It was even a subject of debate within our own group. By using the second analysis and definitions 3,4 , and 5, patients who died in a skilled nursing facility within 30 days would be counted as an operative death, but those who died after 30 days would not be counted. Limitations of our study include that the data came from an administrative dataset that some people would challenge as not as precise as clinical data. The data are dependent on International Classification of Diseases, version 9 codes for diagnosis and on the California Statistics Death Files, and 2009 has the most current available death files, which is why we used data from 2009. A lack of (1:07:48.4) XXX in identifiers, which is why we did 2 separate analyses. Eight percent of patients could not be tracked. Patients who were transferred to skilled nursing facilities were not counted in mortality calculations in our second analysis unless they died within 30 days.

Mortality rates from the same procedure can be variable and depend on the definition chosen, as well as the ability and tenacity of programmers to pursue data. We found that up to $20 \%$ of hospitals were not able to track their patients long-term. Comparative outcome reporting should require validation, and this study shows the importance of the definition of operative mortality and the need for accurate reporting of (1:08:28.8) XXX clinical registries such as the STS, and comparison of PCI versus CABG is complicated by the difference in definitions between STS-NDB and the ACC-NCDR.

Dr S. Moffatt-Bruce (Columbus, Ohio). The number of organizations that are issuing reports on hospitals and physician quality are increasing, and frankly, it has become a cottage industry over the last decade. Despite a positive intent to provide a metric of safe and patient-centered care, these measures are being put forward in public data, but I think it leads to contradiction. I think it leads to confusion for not only the public and providers but also the governing boards and ultimately the public's ability to make decisions. You have outlined that, and you've really set the platform as to why this is so important. In 2008, Rothberg had an article in Health Affairs that showed there was variability not only in public reporting between institutions but also within the same institution, and this was pertinent to not only Consumer Reports that you mention in your talk, which is a newcomer to the public reporting arena, but also in the Leapfrog, Healthgrades, Hospital Compare, and U.S. News \& World Report. In an attempt to render some clarity to this important public reporting, the Association of American Medical Colleges in 2010 convened a group of experts to put forth guiding principles for public reporting of performance data. We came up with 3 guiding principles, and I want to comment on your proposal as it portends to those 3 . The 3 different guiding principles are around purpose, transparency, and validity. Purpose- that the target audience and intended purpose be well defined-you have done that today in your talk and in your article. Transparency-all information necessary to understand the data be available and that the limitations be clear-I think you've clearly outlined the limitations of your data, but perhaps because you don't have a risk adjustment, which I'll speak to, it's not meeting the mark. Validity-an accurate reflection of the characteristic being measured-well you're dead or alive, so I think that you've met that, but perhaps the meaningful time frame is lacking. In 2015, Peter Pronovost published another article: "National Hospital Rating Systems Share Few Common Scores and May Generate Confusion Instead of Clarity." I think that clearly sums up where we are at this point in our adventure in public reporting of performance, and I think there remain 700 top 100 hospitals depending on who is doing the ranking and who is reading them. I have 3 questions, and perhaps we do not have all the answers today as we all struggle with health care performance measurement. First, your data come from an administrative dataset, and that is kind of the reality of what we work with currently. Do you think, though, considering that was from 2009, that if you were to restudy with more concurrent data that your result would look similar today? 
Dr Maximus. The reason we used 2009, as I mentioned, is because it's the only way we could validate deaths using the California Vital Statistics Death Files. I think it would look similar, because we used the Vital Statistics Death Files to validate those data. I do not think we found many that were not validated. I cannot remember the percentage off the top of my head, but I do not think it was very significant.

Dr Moffatt-Bruce. Okay. Second, I did not see anywhere in your article that there was a risk adjustment, and I do think that raw percentages may drive risk-averse behavior, which is one of the greatest challenges with publicly reported data that we tend not to want to take complicated cases, when it's the right thing to do because it may affect our ranking or the public perception of our performance. I was able to look up your risk-adjusted mortality in the UHC database, which is an academic database that has approximately 114 hospitals, and your performance is very good. It uses 31 variables in the risk adjustment. Do you think that redoing this and looking at some sort of way of including a risk adjustment is important or is not even relevant?

Dr Maximus. I think it's very relevant. It's something we actually talked about doing. We thought for our purposes that this would be a start and then that would be something we would possibly look into doing, because it is something we were debating within our group; it's something we plan on doing.

Dr Moffatt-Bruce. Good. In January 2015, a historic announcement was made by the Health and Human Services Secretary, Sylvia Burnwell, that stated by 2019, $90 \%$ of our reimbursement needs to be tied to value and quality. Many of the deaths in your article were in the postoperative or the postacute phase. How can we, as surgeons, actually impact what happens when our patients leave our doors?

Dr Maximus. That's the issue of where they're transferred to or where they're discharged to. Patients who are discharged to home, I think, at our hospital, we have our nurse practitioners and physician assistants follow-up with them even at home. We'll send them, if need be, to do that. As far as where they're transferred to, I think that's more of an issue. That's harder to control, and that actually brings up the debate of whether skilled nursing facility deaths should be counted or not. Currently they're not required to report their data, so I do not think those deaths are counted; however, there is a debate about that. Should those deaths be counted if your procedure led to a patient dying even in a skilled nursing facility. I think that says something, but again it's hard to control those things and where patients end up, because insurance plays a role, and the patient and family play a role, so sometimes we cannot control all those things.

Dr Wu. I commend your group's research efforts and ability to demonstrate wide variation in outcomes based on different definitions that focus on time and location. I am interested in hearing your opinions and the panelists' opinions on a strategy where you focus on the actual therapeutic approach in terms of mortality. Allow me to give you an example. If a patient has a PCI that results in a coronary artery dissection, and the patient undergoes an emergency $\mathrm{CABG}$ and dies, is that a PCI or CABG death? You can equate that to the intention-to-treat analysis in any clinical trial, and although we look at it as treated, we focus on the intention to treat, and you can take this into thoracic surgery as well. If someone has an esophagoscopy and an iatrogenic perforation and needs an esophagectomy and dies of that, is that an esophagectomy death or an intention to treat esophagoscopy death?

Dr Maximus. That's a great question. As far as I know, the way we looked at it was that it was the initial International Classification of Diseases, 9th Revision diagnosis, and again it's the whole idea, the quality of the care. That's a more difficult thing to do, and as another speaker pointed out, you can do the whole procedure and everything can go perfectly, and the outcome desired sometimes is not accomplished and you end up with a clinical death, so I think that's much more. Measuring quality is a difficult thing. We used all these surrogates and these administrative data say to do this, but I think it is, even through this article, looking at that, very difficult to assess quality.

Dr M. Brennan. This is a great article when it sparks this much discussion, so my point is really around the resources that it takes to accurately collect 30-day or longer outcomes. With the STS database, we link the database with Medicare to try and solve this problem in part, but even at Duke, a 4-decade old Duke database is being shut down and has been shut down this past year because the resources required to follow patients that long are tremendous, and so I would ask you from your perspective, who pays? Who pays for the followup, and if you don't have someone paying for the follow-up, I would argue that we can talk about this as much as we want, it's just not going to happen, and follow-up at 30 days, clinical follow-up in my clinic for example, after I do a PCI is just not adequate. So, I'll put that question to you.

Dr Maximus. To answer the second part of your question, who pays? I am not sure. As far as the first part, tracking the patients is difficult. Again, we found some hospitals where they were unable to track $20 \%$ of their patients even with the accurate record linkage numbers and Social Security numbers. It really depends on the tenacity of the programmer and those tracking those patients, how aggressive they are in tracking. I think some hospitals were good about that and some were not so good, so it just really depends on that, and again, as you mentioned, it's the funding and how much resources they have, and it is a 
difficult thing to be able to track some of these patients long term as mentioned.

Unidentified speaker (St Louis, Mo). It would be important to show the $95 \%$ confidence interval off the point estimates for all 5 of your scores and then statistically discriminate if all 5 scores are different or not, because that essentially is the basis of your recommendation saying that these scores are transferable from one dataset to the other or not, so I would encourage you to do that if you have not already done that in your article.

Dr Maximus. That's something we will be doing in the revised version of our article.

\title{
EDITORIAL COMMENTARY
}

\section{The perils of the body count}

\author{
Tom Treasure, MD, MS, FRCS, FRCP, ${ }^{\mathrm{a}}$ and Samer Nashef, FRCS ${ }^{\mathrm{b}}$
}

\footnotetext{
From the ${ }^{\mathrm{a}}$ Clinical Operational Research Unit, University College London, United Kingdom; and ${ }^{\mathrm{b}}$ Papworth Hospital, Cambridge, United Kingdom.

Disclosures: Authors have nothing to disclose with regard to commercial support.

Received for publication Oct 22, 2015; accepted for publication Dec 12, 2015; available ahead of print Jan 22, 2016.

Address for reprints: Tom Treasure, MD, MS, FRCS, FRCP, Clinical Operational Research Unit, University College London, 4 Taviton St, London WC1H 0BT, United Kingdom (E-mail: tom.treasure@gmail.com).

J Thorac Cardiovasc Surg 2016;151:1110-1

$0022-5223 / \$ 36.00$

Copyright $(5) 2016$ by The American Association for Thoracic Surgery

http://dx.doi.org/10.1016/j.jtcvs.2015.12.025
}

The public, our patients, and their families might be surprised to discover that doctors have difficulty tallying how many people die after cardiac interventions, and that the question merited a piece of published statistical analysis. Maximus and colleagues ${ }^{1}$ document how the wider they searched and the longer after the intervention, the more deaths they were able to find. The attrition continues to 90 days, ${ }^{2}$ making it possible to add yet more definitions of operative mortality to their 5 to take that into account.

A perfect system would capture death following a procedure irrespective of where it occurs, provide correct dates for all deaths, and record in reasonable detail the cause of death. Such a record ideally would allow for attribution of a causal relationship between the death and (1) the quality of the intervention, (2) the underlying disease process, and (3) causes unrelated to either. ${ }^{3}$ In any analysis of mortality statistics, interpretation must be fair and cogent; thus, Maximus and colleagues steer clear of making comparisons between surgical and percutaneous interventions. It behooves the reader to be similarly cautious. The paper is about retrieving the fact and date of the death, whenever and wherever it occurred. The columns in Figures 2 and 3 are counts of absolute numbers of deaths, not relative death rates.

To emphasize this point, consider the category of percutaneous coronary intervention (PCI) for acute coronary syndrome (ACS). In the early years, coronary

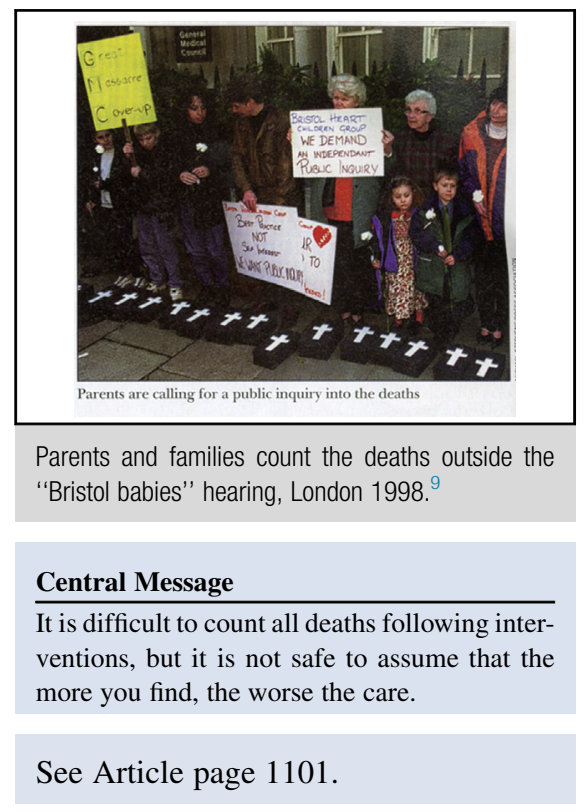

surgery was occasionally performed for evolving myocardial infarction with some success, mostly anecdotal-for example, opportunistic cases with the patient already in the hospital and an available surgical team. But emergency coronary surgery for evolving infarction ${ }^{4,5}$ became a serious proposition in the light of remarkable results in 227 patients from a dedicated service in Spokane, Washington from 1972. ${ }^{6}$ Later, when angioplasty became available, it was reserved for elective cases with the safest disease and with a surgeon close at hand. Its application to saving lives and heart muscle in evolving infarction as close as possible to the onset, whatever the hour, took some time to emerge, but it is now the intervention that cardiac surgeons would want for themselves. The context of PCI for ACS requires that some patients will die despite the intervention and others will die as a consequence of their disease during 